\title{
Association of the LOX-1 rs1050283 Polymorphism with Risk for Atherosclerotic Cerebral Infarction and its Effect on sLOX-1 and LOX-1 Expression in a Chinese Population
}

\author{
Xin Guo ${ }^{1}$, Yuanyuan Xiang ${ }^{1}$, Heng Yang ${ }^{2}$, Lijin Yu ${ }^{1}$, Xiangdong Peng ${ }^{1}$ and Ren Guo ${ }^{1}$ \\ Xin Guo and Yuanyuan Xiang contributed equally to this work. \\ ${ }^{1}$ Department of Pharmacy, The Third Xiangya Hospital, Central South University, Changsha, Hunan, China \\ ${ }^{2}$ Department of Neurology, The Third Xiangya Hospital, Central South University, Changsha, Hunan, China
}

\begin{abstract}
Aims: The interaction between lectin-like oxidized low density lipoprotein (LDL) receptor-1 (LOX-1) and oxidized LDL (ox-LDL) has been viewed as an important pathogenic factor for cardiovascular diseases. This study aimed to explore the association of a functional polymorphism rs 1050283 in the 3 -untranslated region of the LOX-1 gene with atherosclerotic cerebral infarction (ACI) susceptibility, and we also investigated the effects of the rs 1050283 polymorphism on LOX-1 expression and serum levels of sLOX-1 in patients with ACI.

Methods: A case-controlled study was performed in 526 patients with ACI and 640 healthy controls. Genotyping was performed by DNA sequencing method. Real-time PCR and Western blotting were used to determine the level of LOX-1 expression. Serum levels of sLOX-1 were quantified using ELISA according to the manufacturer's instruction.

Results: The results of the present study showed that the frequency of rs $1050283 \mathrm{~T}$ allele was significantly higher in patients with ACI than in healthy controls. We also found that the rs 1050283 polymorphism $\mathrm{T}$ allele was associated with increased LOX-1 expression at mRNA and protein levels in patients with ACI. Furthermore, we also observed that among patients with ACI, those with the rs $1050283 \mathrm{~T}$ allele showed an increased serum level of sLOX-1.

Conclusion: Our research demonstrated that the rs1050283 T allele of LOX-1 is strongly associated with an increased risk for ACI in a Chinese population, which also affects levels of LOX-1 and sLOX1.
\end{abstract}

See editorial vol. 24: 566-568

Key words: Atherosclerotic cerebral infarction, Oxidized low density lipoprotein, Lectin-like oxidized LDL receptor-1, rs1050283 polymorphism

\section{Introduction}

Atherosclerotic cerebral infarction (ACI) is an important type of ischemic stroke and is also an important cause of mortality and disability in China ${ }^{1)}$. Atherosclerosis (AS) is the fundamental pathogenesis

Address for correspondence: Ren Guo, Department of Pharmacy, The Third Xiangya Hospital, Central South University, Changsha, Hunan, 410013, China.

E-mail: grfw2012@aliyun.com

Received: April 24, 2016

Accepted for publication: September 6, 2016 for ACI and many other ischemic cardio-cerebrovascular diseases, including coronary heart disease and thromboembolic disease ${ }^{2)}$. Though there are many theories concerning the process of $\mathrm{AS}^{3-5)}$, thus far, the pathogenesis of AS has not been fully addressed because of a complex etiology involving genetic and environmental contributions; therefore, limited effective prevention and control by drugs have been used to treat the AS-related diseases, particularly ACI.

According to the most accepted inflammationinjury-reaction theory, AS is a chronic inflammatory disease caused by multiple etiological factors. Endo- 
thelial damage caused by oxidized-low density lipoprotein (ox-LDL) is involved in the early stage of $A S^{6-8)}$. Currently, many ox-LDL receptors have been found and identified on the AS-related cells, such as endothelial cells, vascular smooth muscle cells (VSMCs), monocytes, macrophages, and foam cells ${ }^{9}, 10$ ). Most of the receptors belong to scavenger receptor family, and their interactions with ox-LDL may display a crucial role in the process of AS. However, subsequent studies have demonstrated that the expression of these receptors in endothelial cells is very low, therefore, the actual role of the scavenger receptors in AS was limited.

The molecular mechanism underlying the activation, dysfunction, and damage of endothelia cells was not fully elucidated until the discovery of lectin-like oxidized LDL receptor-1 (LOX-1) in the 20th century. LOX-1 was reported for the first time by Sawamura et al in bovine aortic endothelial cells which consisted of 270 amino acid residues with a relative molecular weight at $30872^{11)}$. Human LOX-1 is a type II single transmembrane protein which belongs to type $\mathrm{C}$ selectin family, but the structure and sequence of LOX-1 is different from any known scavenger receptors. LOX-1 is composed of four protein domains: $\mathrm{N}$ terminal cytoplasmic, transmembrane, link, and C-terminal lectin-like domain ${ }^{12)}$. The LOX 1 gene is a single copy gene with $19 \mathrm{~kb}$ nucleotides and eight exons. Emerging evidence has demonstrated that LOX-1 mainly expresses on AS-related cells (endothelia cells, VSMCs, and monocytes) and exhibits high ligand specificity to ox-LDL (every three LOX-1 receptors combined with an ox-LDL) ${ }^{13)}$.

Accumulated studies have proved the association of LOX-1 with AS in both in vitro and in vivo experiments. Vascular endothelial dysfunction is the initiating factor for AS. After activation by its ligand oxLDL, LOX-1 can induce the damage of endothelial cells, promote adhesion of monocytes, trigger the apoptotic mechanism of endothelial cells, and finally lead to the formation and development of $\mathrm{AS}^{14,15}$. Activated LOX-1 also functions as an inducer of reactive oxygen species (ROS) in endothelia cells by stimulating NADPH oxidase and mitochondrial electron transport chain pathways ${ }^{16)}$. The produced ROS can directly interact with nitric oxide (NO) and result in increased levels of peroxinitrites which subsequently inactivate $\mathrm{NO}$ and induce the dysfunction of the endothelium. VSMCs play an important role in regulating the vasomotor function of vessels; proliferation and migration of VSMCs are also involved in the pathogenesis of AS in early stages. Elevated levels of ox-LDL could induce LOX-1 expression in VSMCs, particularly in atherosclerotic plaques, by activating
ERK, p38MAPK, and PI3K pathways ${ }^{17,}{ }^{18)}$. Furthermore, some studies confirmed that the adhesion capacity of monocytes was mediated by LOX-1 in the process of $A S^{19)}$.

Though the role of LOX-1 in AS has been regarded as a research focus in recent years, there are limited studies concerning the association of certain single nucleotide polymorphism (SNP) in the LOX-1 gene with the susceptibility to ACI. Therefore, here we conducted a case-controlled study to explore the possible role of a functional SNP rs1050283 present in the $3^{\prime}$-untranslated region $\left(3^{\prime}\right.$-UTR) of the LOX1gene in ACI. Moreover, LOX-1 can be hydrolysed and released into the blood by specific proteases; the hydrolysis product, known as sLOX-1, was recently reported to be a potential biomarker for cardiovascular diseases ${ }^{20)}$. Therefore, we also analyzed the association of the rs1050283 polymorphism with serum levels of sLOX-1 to identify the feasibility of using the rs 1050283 polymorphism as a new predictor for ACI.

\section{Methods}

\section{Subjects}

The present study included 526 patients diagnosed with ACI and 640 healthy controls from unrelated Chinese Han population in the Hunan Province of China. The patients were hospitalized in the Department of Neurology, the Third Xiangya Hospital of Central South University between July 2012 and December 2015. All patients with ACI were confirmed by brain CT and/or MRI with clinical neurological examination, and macroangiopathy was defined by transcranial doppler ultrasonography (TCD), carotid color ultrasonography, and head magnetic resonance angiography (MRA). The healthy controls were recruited from the health management center of the Third Xiangya Hospital, matched by sex and age, and without a history of hypertension, diabetes mellitus, and clinical or radiological evidence of stroke and other neurological diseases. Five-milliliter venous blood sample was drawn into ethylenediaminetetraacetic acid-containing tubes. Plasma and peripheral leukocytes were isolated immediately and separately stored at $-20^{\circ} \mathrm{C}$ until analysis. Serum levels of alanine transaminase (ALT), aspartate transaminase (AST), total cholesterol (TC), triglyceride (TG), highdensity lipoprotein (HDL), LDL, creatinine $(\mathrm{Cr})$, and sLOX-1 were measured in all participants. Detailed personal information (age, gender, body mass index, and history of hypertension and diabetes) of all patients and controls were collected using a structured questionnaire.

Written informed consent was obtained from all 
participants. The study was approved by the ethical committee of the Third Xiangya Hospital of Central South University.

\section{Genotyping}

Genomic DNA samples were extracted from whole blood samples using a DNA Purification Kit (Promega, Madison, USA). The LOX-1 rs1050283 polymorphism was genotyped by DNA sequencing method completed by Sangon Biological Company. For genotyping, the following primers for PCR amplification were designed by Primer Premier 5.0: $5^{\prime}$-ATT TGAAGGCTCTGGAAG-3' (sense) and 5' -TTCTTG ATTTCGGAATGG-3' (antisense). PCR reaction was performed in a final volume of $20 \mu \mathrm{l}$, containing $10 \mu \mathrm{l}$ of $2 \times$ PCR buffer, $1 \mu \mathrm{l}$ of each primer (10 pmol), $2 \mu \mathrm{l}$ of the genomic DNA template, and $6 \mu \mathrm{l}$ of $\mathrm{ddH}_{2} \mathrm{O}$. The PCR amplification condition is described as follow: a denaturation step at $95^{\circ} \mathrm{C}$ for $5 \mathrm{~min}$, followed by 37 cycles of denaturation at $95^{\circ} \mathrm{C}$ for $30 \mathrm{~s}$, annealing at $60^{\circ} \mathrm{C}$ for $45 \mathrm{~s}$, extension at $72^{\circ} \mathrm{C}$ for $30 \mathrm{~s}$, and a final incubation at $72^{\circ} \mathrm{C}$ for $10 \mathrm{~min}$.

\section{Isolation of Peripheral Blood Mononuclear Cells (PBMCs) from Patients with ACI and Controls}

PBMCs were collected from the whole blood samples of patients with ACI and healthy controls. After centrifugation at $2000 \mathrm{~g}$ for $30 \mathrm{~min}$ upon $5 \mathrm{ml}$ Ficoll-Hypaque gradients (Sigma, USA), the monocytes from the buffy coat were extracted and washed twice with ice cold PBS before suspending in RPMI 1640 containing $10 \%$ fetal calf serum (FCS). Then the cells were cultured in a $5 \% \mathrm{CO}_{2}$ incubator at $37^{\circ} \mathrm{C}^{21}$.

\section{Real-Time PCR Analysis}

To assess differential LOX-1 mRNA expression in PBMCs from patients with ACI and healthy controls, real-time PCR was performed according to manufacturer's instructions using ABI 7500 real-time PCR system using SYBR Green method. Sequences of primers were as follows: LOX-1: $5^{\prime}$-CTGATGACTCC TCCCCAGAA- $3^{\prime}$ (sense) and 5'-CGAGCATCAAGA TGGAGACA-3 ${ }^{\prime}$ (antisense) and GAPDH (endogenous control): 5'-CTGC ACCA CCAACTGCTTAG $-3^{\prime}$ (sense) and 5'-AGGTC CACCACTGACACGTT $-3^{\prime}$ (antisense). Relative LOX-1 mRNA expression was normalized to the expression level of GAPDH. All amplification reactions were performed in triplicate.

\section{Western Blot}

Protein was extracted from PBMCs in six-well culture-plates with RIPA lysis buffer (Beyotime Biotech, China). The BCA protein quantitation kit was used to determine the protein content of each sample.
An equal amount of $10 \mu \mathrm{g}$ total protein was separated on SDS-polyacrylamide gel electrophoresis(SDSPAGE) (Beyotime Biotech, China) and then transferred onto polyvinylidene fluoride (PVDF) membranes (EMD Millipore, Billerica, MA, USA). The PVDF membranes were incubated in blocking solution ( $5 \%$ non-fat milk) for $1 \mathrm{~h}$ at room temperature and then incubated in LOX-1 (Abcam, UK) or GAPDH (Abcam, UK) primary antibody overnight at $4{ }^{\circ} \mathrm{C}$ followed by the addition of horseradish peroxidase-conjugated secondary antibody. The immunoblots were detected using an enhanced chemiluminescence system (ChemiDoc XRS; Bio-Rad, USA), and the relative intensities were analyzed using a Bio-Rad Calibrated Densitometer. We used the following method to compare results in different membranes: when Western blotting was completed, a sample from this Western blot was selected to perform the next Western blotting with other samples. Once Western blotting of all samples was completed, data was homogenized according to the chosen sample.

\section{Determination of Serum Levels of sLOX-1}

Serum levels of sLOX-1 were measured using a sLOX-1 ELISA Kit (R\&D Systems, USA). The intra and inter-assay coefficients of variation were $4 \%$ and $5 \%$, respectively.

\section{Statistical Analysis}

Statistical analysis was performed using the software SSPS 16.0. Frequencies of the genotypes and alleles of the LOX-1 polymorphism were evaluated using the $\chi^{2}$ test. Differences among the groups were compared using the one-way ANOVA test. Descriptive results of continuous variables were expressed as mean \pm SD. A $P$ value $<0.05$ was considered significant.

\section{Results}

\section{Clinical and Laboratory Characteristics of Patients with ACI and Healthy Controls}

The distribution of clinical and risk factors are summarized in Table 1. Patients with ACI showed increased levels of systolic blood pressure, diastolic blood pressure, and serum LDL and lower levels of HDL. Patients with ACI also showed a higher prevalence of smoking. No differences were found between patients with ACI and healthy controls with respect to gender, age, and other indexes.

\section{The rs1050283 Genotyping}

The rs1050283 polymorphism of LOX-1 was genotyped by the sequencing method. As shown in 
Table 1. Clinical characteristics of the ACI patients and healthy controls

\begin{tabular}{lccc}
\hline Characteristics & $\begin{array}{c}\text { ACI } \\
(n=526)\end{array}$ & $\begin{array}{c}\text { Controls } \\
(n=640)\end{array}$ & $P$ \\
\hline Gender (male/female) & $299 / 227$ & $332 / 308$ & NS \\
Age $($ years $)$ & $63.16 \pm 8.27$ & $62.58 \pm 7.82$ & NS \\
BMI $\left(\mathrm{kg} / \mathrm{m}^{2}\right)$ & $24.21 \pm 1.89$ & $23.26 \pm 2.12$ & NS \\
SBP $(\mathrm{mmHg})$ & $132 \pm 18$ & $118 \pm 15$ & $<0.001$ \\
DBP $(\mathrm{mmHg})$ & $81 \pm 12$ & $75 \pm 8$ & $<0.001$ \\
Cr $(\mathrm{mmol} / \mathrm{L})$ & $88.54 \pm 15.41$ & $87.92 \pm 13.42$ & $\mathrm{NS}$ \\
HDL-C $(\mathrm{mmol} / \mathrm{L})$ & $1.13 \pm 0.43$ & $1.49 \pm 0.29$ & $<0.001$ \\
LDL-C $(\mathrm{mmol} / \mathrm{L})$ & $2.88 \pm 0.63$ & $2.06 \pm 0.64$ & $<0.001$ \\
TG $(\mathrm{mmol} / \mathrm{L})$ & $1.75 \pm 1.02$ & $1.72 \pm 0.82$ & $\mathrm{NS}$ \\
TC $(\mathrm{mmol} / \mathrm{L})$ & $4.46 \pm 0.72$ & $4.41 \pm 0.85$ & $\mathrm{NS}$ \\
Hypertension $(\%)$ & $318(60.46)$ & $0(0)$ & $<0.001$ \\
Positive history of smoking $\%)$ & $240(45.63)$ & $179(27.97)$ & $<0.001$ \\
Positive history of alcohol consumption $(\%)$ & $147(27.95)$ & $165(25.78)$ & NS \\
Diabetes mellitus $(\%)$ & $102(19.39)$ & 0 & $<0.001$ \\
\hline
\end{tabular}

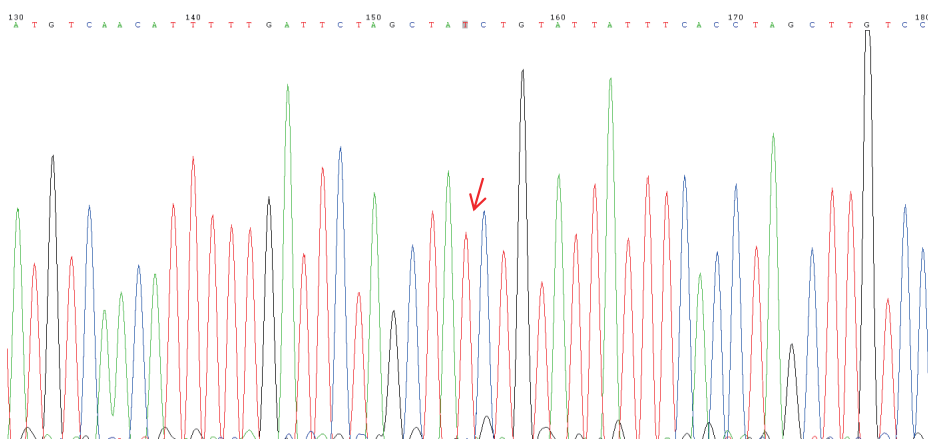

A: TT genotype

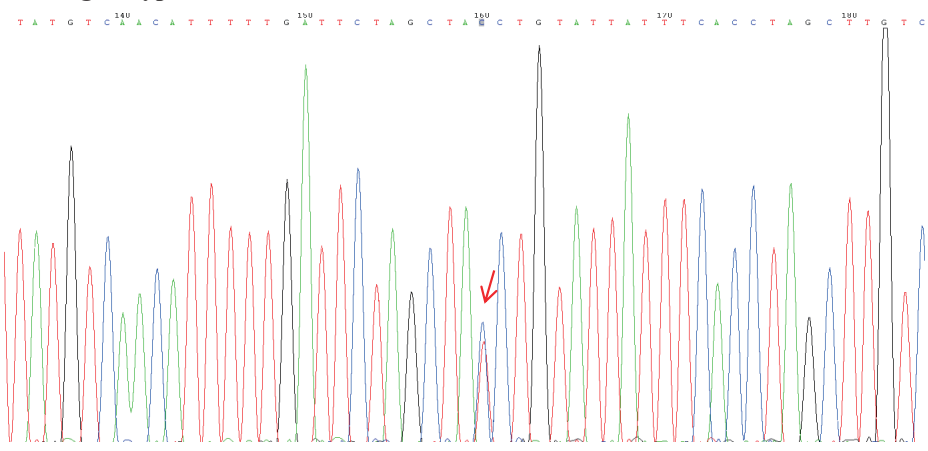

B: CT genotype

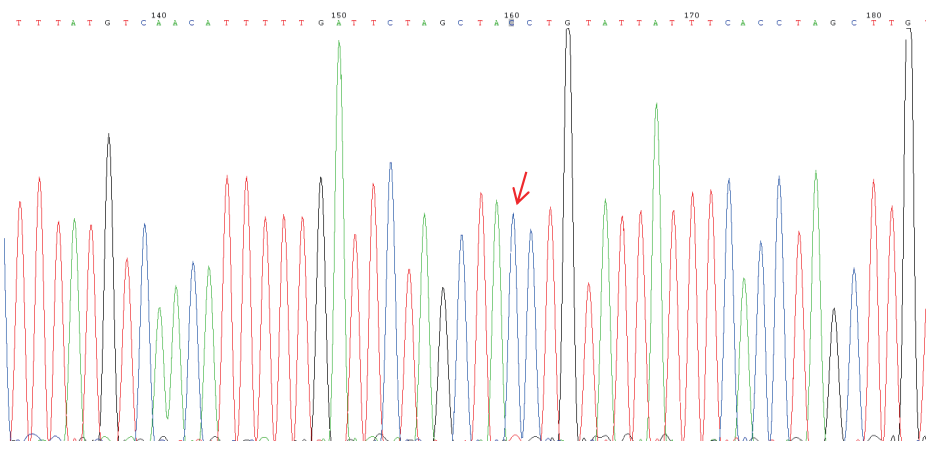

$\mathrm{C}$ : CC genotype
Fig. 1. DNA sequencing diagram of the LOX-1 rs1050283 polymorphism

(A) TT genotype, (B) CT genotype, and (C) CC genotype. 
Table 2. Genotype distribution and allele frequency of LOX-1 rs 1050283 polymorphism in ACI patients and healthy controls

\begin{tabular}{|c|c|c|c|c|c|c|}
\hline & \multirow[t]{2}{*}{$n$} & \multicolumn{3}{|c|}{ Genotype(\%) } & \multicolumn{2}{|c|}{ Allele(\%) } \\
\hline & & TT & $\mathrm{CT}$ & $\mathrm{CC}$ & $\mathrm{T}$ & $\mathrm{C}$ \\
\hline ACI patients & 526 & $57(10.8)$ & $184(35.0)$ & $285(54.2)$ & $298(28.3)$ & $754(71.7)$ \\
\hline Controls & 640 & $45(7.0)$ & $193(30.2)$ & $402(62.8)$ & $283(22.1)$ & 997 (77.9) \\
\hline$\chi^{2}$ & & & 10.507 & & 11.933 & \\
\hline$P$-value & & & 0.005 & & 0.001 & \\
\hline OR (95\%CI) & & & & & $1.392(1.154-1.681)$ & \\
\hline
\end{tabular}

Table 3. Clinical characteristics of the ACI patients and healthy controls ( $n=120$, respectively)

\begin{tabular}{lccc}
\hline Characteristics & $\begin{array}{c}\text { ACI } \\
(n=120)\end{array}$ & $\begin{array}{c}\text { Controls } \\
(n=120)\end{array}$ & $P$ \\
\hline Gender (male/female) & $72 / 48$ & $68 / 52$ & NS \\
Age (years) & $62.84 \pm 7.69$ & $62.41 \pm 7.25$ & NS \\
BMI $\left(\mathrm{kg} / \mathrm{m}^{2}\right)$ & $24.21 \pm 1.89$ & $23.26 \pm 2.12$ & $\mathrm{NS}$ \\
SBP $(\mathrm{mmHg})$ & $128 \pm 16$ & $120 \pm 14$ & $<0.05$ \\
DBP $(\mathrm{mmHg})$ & $78 \pm 15$ & $74 \pm 10$ & $<0.05$ \\
Cr $(\mathrm{mmol} / \mathrm{L})$ & $90.68 \pm 13.46$ & $89.35 \pm 12.67$ & $\mathrm{NS}$ \\
HDL-C $(\mathrm{mmol} / \mathrm{L})$ & $1.15 \pm 0.38$ & $1.52 \pm 0.42$ & $<0.001$ \\
LDL-C $(\mathrm{mmol} / \mathrm{L})$ & $2.85 \pm 0.56$ & $2.05 \pm 0.62$ & $<0.001$ \\
TG $(\mathrm{mmol} / \mathrm{L})$ & $1.76 \pm 1.13$ & $1.75 \pm 0.91$ & $\mathrm{NS}$ \\
TC $(\mathrm{mmol} / \mathrm{L})$ & $4.38 \pm 0.85$ & $4.45 \pm 0.81$ & $\mathrm{NS}$ \\
Hypertension $(\%)$ & $75(62.5)$ & $0(0)$ & $<0.001$ \\
Positive history of smoking $\%)$ & $50(41.67)$ & $38(31.67)$ & $<0.001$ \\
Positive history of alcohol consumption (\%) & $32(26.67)$ & $34(28.33)$ & $\mathrm{NS}$ \\
Diabetes mellitus $(\%)$ & $25(20.83)$ & 0 & $<0.001$ \\
\hline
\end{tabular}

Fig. 1, three genotypes (TT, CT, and CC) were identified in this study.

\section{Association of the rs1050283 Polymorphism with Risk for ACI}

The distribution of genotypes was consistent with the Hardy-Weinberg equilibrium in patients with ACI and healthy controls. As shown in Table 2, the LOX-1 rs1050283 TT genotype was overrepresented in patients with ACI compared with the healthy controls $\left(10.8 \%\right.$ vs $7.0 \%, \chi^{2}=10.51, P<$ 0.01 ). The comparison of the genotype distribution between patients with ACI and healthy controls also demonstrated that the frequency of the rs $1050283 \mathrm{~T}$ allele in patients with ACI was significantly higher than that in healthy controls $\left(28.3 \%\right.$ vs $22.1 \%, \chi^{2}$ $=11.93, P<0.01, \mathrm{OR}=1.39$, 95\% CI: $1.15-1.68)$.

\section{The Difference of LOX-1 Expression between Patients with ACI and Healthy Controls}

Given the important role of LOX-1 expression in the process of AS, we extracted PBMCs from 120 patients with ACI and 120 healthy controls randomly to determine the LOX-1 expression (the background data of these subjects are listed in Table 3). In our study, increased LOX-1 expression at the mRNA and protein levels was observed in patients with patients with ACI compared with that in healthy controls (Fig. 2A and Fig. 2B), which pointed to an enhanced function of LOX-1 in patients with ACI. Our findings were in line with those of the previous reports that increased levels of LOX-1 were associated with ASrelated diseases.

\section{The Effect of the rs1050283 Polymorphism on LOX-1 Expression}

Here we also tried to explore whether the rs1050283 polymorphism affected the LOX-1 expression in PBMCs. We used real-time PCR and Western blot to measure the LOX-1 expression from 135 randomly selected patients with ACI $(n=45$ in each genotype group; the background data of these subjects are 

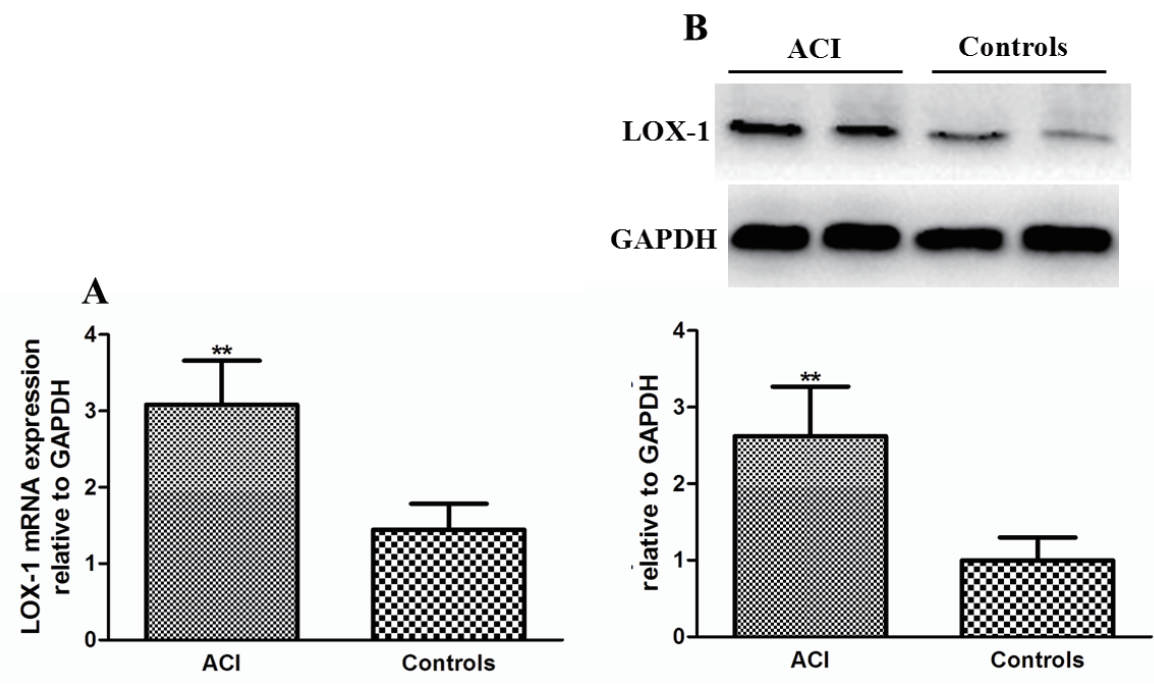

Fig. 2. The difference in LOX-1 expression between patients with ACI and healthy controls

(A) LOX-1 mRNA expression in patients with ACI and healthy controls. Data are expressed as mean $\pm \mathrm{SD}, n=120$ in each group. LOX-1 mRNA expression in PBMCs was determined by real-time PCR and expressed as ratio of the control. ${ }^{* *} P<0.01$ vs. healthy controls. (B) LOX-1 protein expression in patients with ACI and healthy controls. Data are expressed as mean $\pm S D$, $n=120$ in each group. LOX-1 protein expression in PBMCs was measured by Western blot and expressed as ratio of the control. ${ }^{* *} P<0.01$ vs. healthy controls. ACI: atherosclerotic cerebral infarction patients and controls: healthy controls.

Table 4. Clinical characteristics of the subjects from 3 genotype groups in ACI patients ( $n=45$, respectively)

\begin{tabular}{|c|c|c|c|c|}
\hline Characteristics & $\begin{array}{c}\text { TT } \\
(n=45)\end{array}$ & $\begin{array}{c}\text { CT } \\
(n=45)\end{array}$ & $\begin{array}{c}\text { CC } \\
(n=45)\end{array}$ & $P$ \\
\hline Gender (male/female) & $24 / 21$ & $26 / 19$ & $22 / 23$ & NS \\
\hline Age (years) & $62.18 \pm 6.54$ & $64.16 \pm 5.89$ & $63.28 \pm 7.64$ & NS \\
\hline BMI $\left(\mathrm{kg} / \mathrm{m}^{2}\right)$ & $23.72 \pm 1.69$ & $24.15 \pm 1.47$ & $24.55 \pm 2.33$ & NS \\
\hline SBP (mmHg) & $136 \pm 12$ & $126 \pm 16$ & $130 \pm 9$ & NS \\
\hline $\mathrm{DBP}(\mathrm{mmHg})$ & $84 \pm 17$ & $79 \pm 14$ & $82 \pm 10$ & NS \\
\hline $\mathrm{Cr}(\mathrm{mmol} / \mathrm{L})$ & $84.31 \pm 11.59$ & $89.43 \pm 15.87$ & $91.20 \pm 17.24$ & NS \\
\hline HDL-C (mmol/L) & $1.12 \pm 0.44$ & $1.21 \pm 0.52$ & $1.15 \pm 0.39$ & NS \\
\hline LDL-C (mmol/L) & $2.76 \pm 0.48$ & $2.92 \pm 0.57$ & $2.84 \pm 0.62$ & NS \\
\hline $\mathrm{TG}(\mathrm{mmol} / \mathrm{L})$ & $1.78 \pm 1.02$ & $1.68 \pm 1.22$ & $1.73 \pm 0.95$ & NS \\
\hline TC (mmol/L) & $4.36 \pm 0.74$ & $4.42 \pm 0.88$ & $4.27 \pm 0.62$ & NS \\
\hline Hypertension (\%) & $26(57.78)$ & $28(62.22)$ & $25(55.56)$ & NS \\
\hline Positive history of smoking (\%) & $21(46.67)$ & $20(44.44)$ & $22(48.89)$ & NS \\
\hline Positive history of alcohol consumption (\%) & $12(26.67)$ & $14(31.11)$ & $12(26.67)$ & NS \\
\hline Diabetes mellitus (\%) & $8(17.78)$ & $11(24.44)$ & $10(22.22)$ & NS \\
\hline
\end{tabular}

listed in Table 4). Our results demonstrated that among patients with ACI, carriers of the rs $1050283 \mathrm{~T}$ allele showed higher LOX-1 expression at the mRNA and protein levels (Fig. 3A and Fig. 3B). However, we failed to observe an apparent association of LOX-1 rs1050283 polymorphism with LOX-1 expression in healthy controls (data not shown). Therefore, these results indicated that the rs1050283 polymorphism might be associated with impaired post-transcription modification of LOX-1 and the process and severity of ACI; patients with ACI carried the rs $1050283 \mathrm{~T}$ allele might show a more severe status of disease because of 
B

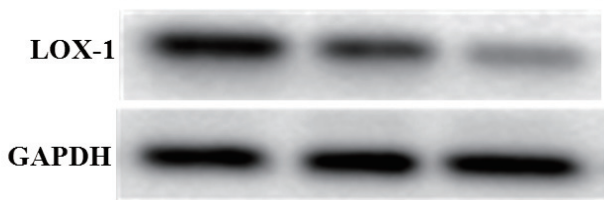

A

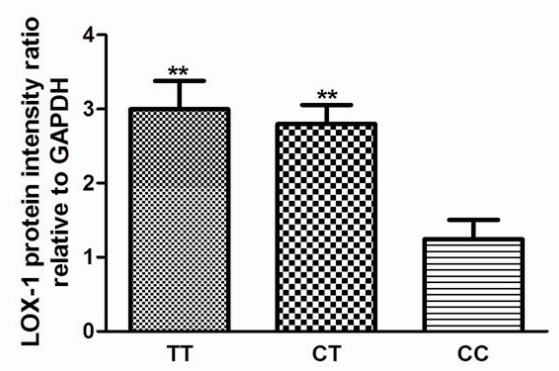

Fig. 3. Effects of the LOX-1 rs1050283 polymorphism on LOX-1 expression in patients with ACI

(A) The difference in LOX-1 mRNA expression between different genotypes. Data are expressed as mean $\pm \mathrm{SD}, n=45$ in each group. LOX- 1 mRNA expression in PBMCs was determined by real-time PCR and expressed as ratio of the control. ${ }^{* *} P<0.01$ vs. CC genotype group. (B) The difference of LOX-1 protein expression between different genotypes. Data are expressed as mean \pm SD, $n=45$ in each group. LOX-1 protein expression in PBMCs was measured by Western blot and expressed as ratio of the control. ${ }^{* *} P<0.01$ vs. CC genotype group. TT: TT genotype, CT: CT genotype, and CC: CC genotype.

Table 5. Clinical characteristics of the ACI patients and healthy controls ( $n=240$, respectively)

\begin{tabular}{lccc}
\hline Characteristics & $\begin{array}{c}\text { ACI } \\
(n=240)\end{array}$ & $\begin{array}{c}\text { Controls } \\
(n=240)\end{array}$ & $P$ \\
\hline Gender (male/female) & $128 / 112$ & $123 / 117$ & NS \\
Age (years) & $64.32 \pm 9.66$ & $63.39 \pm 8.57$ & NS \\
BMI $\left(\mathrm{kg} / \mathrm{m}^{2}\right)$ & $23.74 . \pm 1.75$ & $23.18 \pm 2.06$ & $\mathrm{NS}$ \\
SBP $(\mathrm{mmHg})$ & $128 \pm 15$ & $116 \pm 12$ & $<0.001$ \\
DBP $(\mathrm{mmHg})$ & $78 \pm 14$ & $73 \pm 10$ & $<0.05$ \\
Cr $(\mathrm{mmol} / \mathrm{L})$ & $92.63 \pm 16.56$ & $89.47 \pm 14.35$ & $\mathrm{NS}$ \\
HDL-C $(\mathrm{mmol} / \mathrm{L})$ & $1.18 \pm 0.36$ & $1.45 \pm 0.49$ & $<0.001$ \\
LDL-C $(\mathrm{mmol} / \mathrm{L})$ & $2.74 \pm 0.52$ & $1.88 \pm 0.72$ & $<0.001$ \\
TG $(\mathrm{mmol} / \mathrm{L})$ & $1.72 \pm 0.82$ & $1.74 \pm 0.71$ & $\mathrm{NS}$ \\
TC (mmol/L) & $4.23 \pm 0.85$ & $4.28 \pm 0.64$ & $\mathrm{NS}$ \\
Hypertension $(\%)$ & $148(61.67)$ & $0(0)$ & $<0.001$ \\
Positive history of smoking (\%) & $103(42.92)$ & $59(24.58)$ & $<0.001$ \\
Positive history of alcohol consumption $(\%)$ & $58(24.17)$ & $62(25.83)$ & $\mathrm{NS}$ \\
Diabetes mellitus (\%) & $53(22.08)$ & 0 & $<0.001$ \\
\hline
\end{tabular}

the higher LOX-1 expression.

\section{The Effect of the rs1050283 Polymorphism on Serum Levels of sLOX-1}

Previous studies have reported the possibility to regard sLOX-1 as a predictor of cardiovascular dis- eases. Therefore, here we examined the effect of the LOX-1 rs1050283 polymorphism on serum levels of sLOX-1. We first randomly selected 240 patients with ACI and 240 healthy controls to detect serum levels of sLOX-1 (the background data of these subjects are listed in Table 5). We found that the patients with 

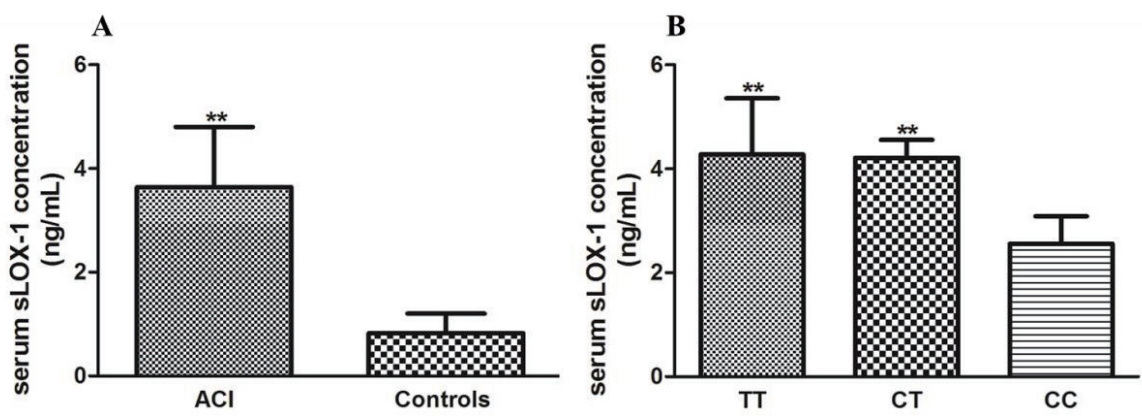

Fig. 4. Serum levels of sLOX-1 in different groups

(A) The difference in levels of sLOX-1 between patients with ACI and healthy controls. Data are expressed as mean $\pm S D, n=240$ in each group. Serum levels of sLOX-1 were assessed using ELISA. ${ }^{* *} P<0.01$ vs. healthy controls. (B) The effect of the LOX-1 rs 1050283 polymorphism on sLOX-1 in patients with ACI. Data are expressed as mean \pm SD, $n=45$ in each genotype group. ${ }^{* *} P<0.01$ vs. CC genotype group. TT: TT genotype, CT: CT genotype, and CC: CC genotype.

ACI displayed a higher level of sLOX-1 than healthy controls. Moreover, the LOX-1 rs1050283 T allele was associated with increased serum levels of sLOX-1 in patients with ACI (Fig. 4A and Fig. 4B, $n=45$ in each genotype group; the background data of these subjects are listed in Table 4), which suggested the potential role of the rs 1050283 polymorphism as a new predictor for cardiovascular diseases.

\section{Discussion}

LOX-1 is a multiple ligand receptor that can interact with ox-LDL, advanced glycosylation end products, activated platelets, neutrophils, apoptotic/ aging cells, C-reactive protein, and bacteria ${ }^{22-26}$. In addition to expression on endothelial cells, LOX-1 is also expressed on other cells, such as VSMCs, fibroblasts, myocardial cells, and macrophages. LOX-1 mediated signaling has been implicated in the development and progression of cardiovascular diseases ${ }^{14,27)}$. By interacting with ox-LOX-1, LOX-1 acts as a key regulator in activating endothelial cells, promoting the adhesion ability of monocytes to the endothelium, and altering VSMCs phenotype by increasing the levels of inflammatory chemokines and adhesion molecules, including monocyte chemotactic protein 1 (MCP-1), E-selectin, P-selectin, and vascular cell adhesion molecule-1 (VCAM-1) ${ }^{28-30)}$. In ApoE knockout mice, pretreatment with an anti-LOX-1 antibody partly recovered the endothelial-dependent diastolic dysfunction of the micro coronary artery induced by high-fat diet ${ }^{31,32)}$. Using immunohistochemical and real-time PCR methods, Neri Serneri et al observed a higher LOX-1 expression in myocardial biopsy specimens from unstable angina patients than from stable angina patients. Furthermore, the exaggerated amount of myocardial ox-LDL and LOX-1 in unstable patients was associated with widespread high grade microvessel inflammation ${ }^{33)}$.

Emerging studies recently focused on the role of the LOX-1 gene polymorphism in cardiovascular diseases. Liu X reported that the G501C polymorphism, not the $3^{\prime}$-UTR-C188T polymorphism, was associated with the susceptibility to cerebral infarction in the northern Chinese Han population ${ }^{34)}$. Man BL, et al. reported that there was a significant association of the TT allele with concurrent stenoses of the extracranial and intracranial vessels in stroke patients ${ }^{35)}$. The IVS4-14 A>G OLR1 polymorphism was also identified to be related to glucose metabolism disturbance, elevated levels of insulin, and lipid peroxidation in patients with metabolic syndrome, and individuals with GG genotype seemed to be more sensitive to these factors ${ }^{36}$. There are also some studies that reported the role of the rs 1050283 polymorphism in coronary artery disease and myocardial infarction ${ }^{37-40)}$. However, thus far, no research has reported the association of the LOX-1 rs 1050283 polymorphism with the susceptibility to ACI. AS mainly depends on the stenosis degree of the vessels and the ischemia degree of affected organs. Although AS is common basis for $\mathrm{ACI}$ and coronary artery disease, the brain and heart are two distinct organs with different blood and collateral circulations. Therefore, although the patients carried the same genotype of LOX-1, they may express different AS-associated diseases. Hence, we think that it is worthwhile to explore the association of the LOX-1 rs1050283 polymorphism with ACI, though some studies have reported the relationship between this polymorphism and coronary artery disease. In this 
study, we first observed the distribution of the rs $1050283 \mathrm{~T}$ allele in patients with $\mathrm{ACI}$ and healthy controls to investigate whether the $\mathrm{T}$ allele can be regarded as an independent risk factor for ACI. Our results showed that the frequency of the rs1050283 T allele was significantly higher in patients with ACI than in healthy controls, and the 95\% CI was $1.15-$ 1.68 , which suggested a high correlativity between the $\mathrm{T}$ allele and susceptibility to ACI. Because the rs1050283 T allele was closely related to ACI, we then asked how this polymorphism affects the process of ACI. A study recently published by Morini E demonstrated that the rs1050286 polymorphism of the LOX-1 gene is involved in the altered LOX-1 expression via modifying miR-24 binding in Hela cells ${ }^{41)}$. Therefore, in our study, we extracted the mRNA and protein in PBMCs from the recruited volunteers to test the effects of the rs 1050283 polymorphism performed on LOX-1 expression in humans. Consistent with our expectations, carriers of the rs $1050283 \mathrm{~T}$ allele were associated with increased LOX-1 expression at the mRNA and protein levels. Our results indicated that the rs 1050283 polymorphism may impact certain miRNAs binding affinity to the $3^{\prime}$-UTR of LOX-1, causing impaired post-transcriptional modification in the presence of the $T$ allele. Using bioinformatics, we found that the binding sites of some miRNAs, including miR-18a, miR-18b, miR-590-3p, and miR-1271, were close to the nucleotide sequences of the rs1050283 polymorphism; therefore, the abnormal expressions of these miRNAs may affect the process of ACI by targeting LOX-1. Hence, the disease process of ACI may cause different expressions of some miRNAs and then induce a different LOX-1 expression among the three genotypes because of different affinities in patients with ACI. Further research to determine whether the interaction between these miRNAs and LOX-1 can be influenced by the rs 1050283 polymorphism is a clear demonstration of the ongoing need for detailed mechanistic understanding of the rs1050283 polymorphism.

Elevated serum levels of sLOX-1 have been observed in patients with acute coronary syndrome and cerebral infarction ${ }^{42-44)}$. Circulating sLOX-1 was also reported to be a more sensitive and specific biomarker for acute coronary syndrome and ST elevation myocardial infarction than troponin $\mathrm{T}$ and heart-type fatty acid binding protein and provided additional diagnostic values when measured in combination with other laboratory indexes ${ }^{20,45,46)}$. As a hydrolysis product of LOX-1, it is of considerable relevance that serum levels of sLOX-1 could be influenced by the rs1050283 polymorphism because we have already identified a definite relationship between this poly- morphism and LOX-1 expression. In line with previous studies, data from our research demonstrated that the serum level of sLOX-1 was significantly higher in patients with ACI than in healthy controls. We further explored the effect of the rs 1050283 polymorphism on serum levels of sLOX-1 in patients with ACI. Some studies have reported the association of the rs1050283 polymorphism with serum levels of sLOX-1 in patients with coronary artery disease, myocardial infarction, Alzheimer's disease, and preeclampsia and healthy old people ${ }^{38,47-50)}$. However, there was no research focused on the association of the rs1050283 polymorphism with serum levels of sLOX-1 in patients with ACI, and data concerning the association of this polymorphism with sLOX-1 seem conflicting. Brinkley TE et al reported that individuals with the CC genotype showed increased levels of sLOX-1 ${ }^{48)}$, whereas other scientists suggested that the $T$ allele of the rs 1050283 polymorphism was associated with increased levels of sLOX-1 ${ }^{38,49,50)}$. Therefore, we think that it is necessary for us to investigate the association among the rs 1050283 polymorphism, LOX-1 expression, and serum levels of sLOX-1 in patients with ACI. In this study, we found that the rs $1050283 \mathrm{~T}$ allele was associated with higher serum levels of sLOX-1 in patients with ACI, which suggested that the rs 1050283 polymorphism may be used as a judgment index for the severity of ACI. Our results would provide supplementary evidence to current research about the role of the LOX-1 rs1050283 polymorphism in diseases.

Therefore, in our study, we investigated the effects of rs1050283 polymorphism on ACI susceptibility and sLOX-1 in Chinese people. We found that the rs1050283 T allele was associated with ACI susceptibility and increased serum levels of sLOX-1 in patients with ACI. Our data highlight the rs 1050283 $\mathrm{T}$ allele as a novel risk factor for ACI. However, the exact mechanism by which the rs 1050283 polymorphism exerts its function remains uncertain. Further studies regarding the role of this gene polymorphism in the cell signaling pathway in AS-related diseases are needed. The sample size of the patients with ACI in our study was limited; further large-scale and multicenter trials are also required to fully unveil the role of the LOX-1 rs 1050283 polymorphism in ACI. Prospectively, targeting certain functional SNP in the LOX-1 gene could represent a promising therapeutic approach to attenuate the process of ACI induced by increased serum levels of ox-LDL.

\section{Acknowledgements}

Sources of Funding: This project was supported 
by Chinese National Science Foundation (No. 81000120) and Hunan Provincial Natural Science Foundation (No.2015JJ3160) to Ren Guo.

\section{Conflicts of Interest}

There are no conflicts of interest.

\section{References}

1) Xu G, Ma M, Liu X, Hankey GJ: Is there a stroke belt in China and why? Stroke, 2013; 44: 1775-1783

2) Hansson GK: Inflammation, atherosclerosis, and coronary artery disease. N Engl J Med, 2005; 352: 1685-1695

3) Hansson GK, Libby P: The immune response in atherosclerosis: a double-edged sword. Nat Rev Immunol, 2006; 6: 508-519

4) Hansson GK: Atherosclerosis--an immune disease: The Anitschkov Lecture 2007. Atherosclerosis, 2009; 202: 2-10

5) Baeyens N, Bandyopadhyay C, Coon BG, Yun S, Schwartz MA: Endothelial fluid shear stress sensing in vascular health and disease. J Clin Invest, 2016; 126: 821828

6) Rafieian-Kopaei M, Setorki M, Doudi M, Baradaran A, Nasri H: Atherosclerosis: process, indicators, risk factors and new hopes. Int J Prev Med, 2014; 5: 927-946

7) Lubrano V, Balzan S: LOX-1 and ROS, inseparable factors in the process of endothelial damage. Free Radic Res, 2014; 48: 841-848

8) Ding Z, Liu S, Wang X, Dai Y, Khaidakov M, Romeo F, Mehta JL: LOX-1, oxidant stress, mtDNA damage, autophagy, and immune response in atherosclerosis. Can J Physiol Pharmacol, 2014; 92: 524-530

9) Horiuchi S, Sakamoto Y, Sakai M: Scavenger receptors for oxidized and glycated proteins. Amino Acids, 2003; 25: 283-292

10) Adachi H, Tsujimoto M: Endothelial scavenger receptors. Prog Lipid Res, 2006; 45: 379-404

11) Sawamura T, Kume N, Aoyama T, Moriwaki H, Hoshikawa H, Aiba Y, Tanaka T, Miwa S, Katsura Y, Kita T, Masaki T: An endothelial receptor for oxidized low-density lipoprotein. Nature, 1997; 386: 73-77

12) Nagase M, Abe J, Takahashi K, Ando J, Hirose S, Fujita T: Genomic organization and regulation of expression of the lectin-like oxidized low-density lipoprotein receptor (LOX-1) gene. J Biol Chem, 1998; 273: 33702-33707

13) Chen X, Zhang T, Du G: Advanced glycation end products serve as ligands for lectin-like oxidized low-density lipoprotein receptor-1(LOX-1): biochemical and binding characterizations assay. Cell Biochem Funct, 2008; 26: $760-770$

14) Sawamura T, Wakabayashi I, Okamura T: LOX-1 in atherosclerotic disease. Clin Chim Acta, 2015; 440: 157-163

15) Pirillo A, Catapano AL: Soluble lectin-like oxidized low density lipoprotein receptor-1 as a biochemical marker for atherosclerosis-related diseases. Dis Markers, 2013; 35: 413-418

16) Zhao W, Ma G, Chen X: Lipopolysaccharide induced
LOX-1 expression via TLR4/MyD88/ROS activated p38MAPK-NF-kappaB pathway. Vascul Pharmacol, 2014; 63: 162-172

17) Zhang Z, Zhang M, Li Y, Liu S, Ping S, Wang J, Ning F, Xie F, Li C: Simvastatin inhibits the additive activation of ERK1/2 and proliferation of rat vascular smooth muscle cells induced by combined mechanical stress and oxLDL through LOX-1 pathway. Cell Signal, 2013; 25: 332-340

18) Aramaki $Y$, Mitsuoka $H$, Toyohara M, Jinnai T, Kanatani K, Nakajima K, Mukai E, Yamada Y, Kita T, Inagaki N, Kume N: Lectin-like oxidized LDL receptor-1 (LOX-1) acts as a receptor for remnant-like lipoprotein particles (RLPs) and mediates RLP-induced migration of vascular smooth muscle cells. Atherosclerosis, 2008; 198: 272-279

19) Li L, Sawamura T, Renier G: Glucose enhances endothelial LOX-1 expression: role for LOX-1 in glucose-induced human monocyte adhesion to endothelium. Diabetes, 2003; 52: 1843-1850

20) Higuma $T$, Abe N, Tateyama $S$, Endo $T$, Shibutani $S$, Yokoyama H, Hanada K, Yamada M, Tomita H, Hanada H, Osanai T, Kume N, Okumura K: Plasma soluble lectin-like oxidized low-density lipoprotein receptor-1 as a novel prognostic biomarker in patients with ST-segment elevation acute myocardial infarction. Circ J, 2015; 79: 641-648

21) Zhang B, Chen M, Yang H, Wu T, Song C, Guo R: Evidence for involvement of the CD40/CD40L system in post-stroke epilepsy. Neurosci Lett, 2014; 567: 6-10

22) Fukui M, Tanaka M, Senmaru T, Nakanishi M, Mukai J, Ohki M, Asano M, Yamazaki M, Hasegawa G, Nakamura $\mathrm{N}$ : LOX-1 is a novel marker for peripheral artery disease in patients with type 2 diabetes. Metabolism, 2013; 62: 935-938

23) Zhu X, Li Z, Li C, Zhang J, Zou Z, Wang J: Ginkgo biloba extract and aspirin synergistically attenuate activated platelet-induced ROS production and LOX-1 expression in human coronary artery endothelial cells. Phytomedicine, 2013; 20: 114-119

24) Wu Z, Sawamura T, Kurdowska AK, Ji HL, Idell S, Fu J: LOX-1 deletion improves neutrophil responses, enhances bacterial clearance, and reduces lung injury in a murine polymicrobial sepsis model. Infect Immun, 2011; 79: 2865-2870

25) Khaidakov M, Wang X, Mehta JL: Potential involvement of LOX-1 in functional consequences of endothelial senescence. PLoS One, 2011; 6: e20964

26) Stancel N, Chen CC, Ke LY, Chu CS, Lu J, Sawamura T, Chen $\mathrm{CH}$ : Interplay between CRP, Atherogenic LDL, and LOX-1 and Its Potential Role in the Pathogenesis of Atherosclerosis. Clin Chem, 2016; 62: 320-327

27) Shaw DJ, Seese R, Ponnambalam S, Ajjan R: The role of lectin-like oxidised low-density lipoprotein receptor-1 in vascular pathology. Diab Vasc Dis Res, 2014; 11: 410-418

28) Feng Y, Cai ZR, Tang Y, Hu G, Lu J, He D, Wang S: TLR4/NF-kappaB signaling pathway-mediated and oxLDL-induced up-regulation of LOX-1, MCP-1, and VCAM-1 expressions in human umbilical vein endothelial cells. Genet Mol Res, 2014; 13: 680-695

29) Wang L, Hu X, Zhang W, Tian F: Angiotensin (1-7) ameliorates angiotensin II-induced inflammation by inhibiting LOX-1 expression. Inflamm Res, 2013; 62: 219-228 
30) Lin J, Xu Y, Zhao T, Sun L, Yang M, Liu T, Sun H, Zhang L: Genistein suppresses smooth muscle cell-derived foam cell formation through tyrosine kinase pathway. Biochem Biophys Res Commun, 2015; 463: 1297-1304

31) Chen X, Zhang H, Hill MA, Zhang C, Park Y: Regulation of Coronary Endothelial Function by Interactions between TNF-alpha, LOX-1 and Adiponectin in Apolipoprotein E Knockout Mice. J Vasc Res, 2016; 52: 372382

32) Xu X, Gao X, Potter BJ, Cao JM, Zhang C: Anti-LOX-1 rescues endothelial function in coronary arterioles in atherosclerotic ApoE knockout mice. Arterioscler Thromb Vasc Biol, 2007; 27: 871-877

33) Neri SG, Coppo M, Bandinelli M, Paoletti P, Toscano T, Micalizzi E, Chiostri M, Boddi M: Exaggerated myocardial oxLDL amount and LOX-1 receptor over-expression associated with coronary microvessel inflammation in unstable angina. Atherosclerosis, 2013; 226: 476-482

34) Liu X, Zhu RX, Li L, He ZY: Association of LOX-1 gene polymorphisms with cerebral infarction in northern Chinese Han population. Lipids Health Dis, 2014; 13: 55

35) Man BL, Baum L, Fu YP, Chan YY, Lam W, Hui CF, Leung WH, Wong KS: Genetic polymorphisms of Chinese patients with ischemic stroke and concurrent stenoses of extracranial and intracranial vessels. J Clin Neurosci, 2010; 17: 1244-1247

36) Palmieri VO, Coppola B, Grattagliano I, Casieri V, Cardinale G, Portincasa P, Palasciano G, Di Serio F: Oxidized LDL receptor 1 gene polymorphism in patients with metabolic syndrome. Eur J Clin Invest, 2013; 43: 41-48

37) Mango R, Clementi F, Borgiani P, Forleo GB, Federici M, Contino G, Giardina E, Garza L, Fahdi IE, Lauro R, Mehta JL, Novelli G, Romeo F: Association of single nucleotide polymorphisms in the oxidised LDL receptor 1 (OLR1) gene in patients with acute myocardial infarction. J Med Genet, 2003; 40: 933-936

38) Chen Q, Reis SE, Kammerer C, Craig WY, LaPierre SE, Zimmer EL, McNamara DM, Pauly DF, Sharaf B, Holubkov R, Bairey MC, Sopko G, Bontempo F, Kamboh MI: Genetic variation in lectin-like oxidized low-density lipoprotein receptor 1 (LOX1) gene and the risk of coronary artery disease. Circulation, 2003; 107: 3146-3151

39) Sentinelli F, Filippi E, Fallarino M, Romeo S, Fanelli M, Buzzetti R, Berni A, Baroni MG: The 3'-UTR C>T polymorphism of the oxidized LDL-receptor 1 (OLR1) gene does not associate with coronary artery disease in Italian CAD patients or with the severity of coronary disease. Nutr Metab Cardiovasc Dis, 2006; 16: 345-352

40) Novelli G, Borgiani P, Mango R, Lauro R, Romeo F: Further evidence that polymorphisms of the OLR1 gene are associated with susceptibility to coronary artery disease and myocardial infarction. Nutr Metab Cardiovasc Dis, 2007; 17: e7-e8, e9-e10

41) Morini E, Rizzacasa B, Pucci S, Polidoro C, Ferre F, Caporossi D, Helmer CM, Novelli G, Amati F: The human rs1050286 polymorphism alters LOX-1 expres- sion through modifying miR-24 binding. J Cell Mol Med, 2016; 20: 181-187

42) Hayashida K, Kume N, Murase T, Minami M, Nakagawa D, Inada T, Tanaka M, Ueda A, Kominami G, Kambara H, Kimura T, Kita T: Serum soluble lectin-like oxidized low-density lipoprotein receptor-1 levels are elevated in acute coronary syndrome: a novel marker for early diagnosis. Circulation, 2005; 112: 812-818

43) Inoue N, Okamura T, Kokubo Y, Fujita $Y$, Sato $Y$, Nakanishi M, Yanagida K, Kakino A, Iwamoto S, Watanabe M, Ogura S, Otsui K, Matsuda H, Uchida K, Yoshimoto R, Sawamura T: LOX index, a novel predictive biochemical marker for coronary heart disease and stroke. Clin Chem, 2010; 56: 550-558

44) Yokota C, Sawamura T, Watanabe M, Kokubo Y, Fujita Y, Kakino A, Nakai M, Toyoda K, Miyamoto Y, Minematsu K: High Levels of Soluble Lectin-Like Oxidized LowDensity Lipoprotein Receptor-1 in Acute Stroke: An Ageand Sex-Matched Cross-Sectional Study. J Atheroscler Thromb, 2016;

45) Kume N, Mitsuoka H, Hayashida K, Tanaka M, Kominami G, Kita T: Soluble lectin-like oxidized LDL receptor-1 (sLOX-1) as a sensitive and specific biomarker for acute coronary syndrome--comparison with other biomarkers. J Cardiol, 2010; 56: 159-165

46) Kobayashi N, Hata N, Kume N, Seino Y, Inami T, Yokoyama S, Shinada T, Tomita K, Kaneshige T, Mizuno K: Soluble lectin-like oxidized low-density lipoprotein receptor-1 as an early biomarker for ST elevation myocardial infarction: time-dependent comparison with other biomarkers: time-dependent comparison with other biomarkers. Circ J, 2011; 75: 1433-1439

47) Mango R, Biocca S, Del VF, Clementi F, Sangiuolo F, Amati F, Filareto A, Grelli S, Spitalieri P, Filesi I, Favalli C, Lauro R, Mehta JL, Romeo F, Novelli G: In vivo and in vitro studies support that a new splicing isoform of OLR1 gene is protective against acute myocardial infarction. Circ Res, 2005; 97: 152-158

48) Brinkley TE, Kume N, Mitsuoka H, Brown MD, Phares DA, Ferrell RE, Kita T, Hagberg JM: Variation in the human lectin-like oxidized low-density lipoprotein receptor 1 (LOX-1) gene is associated with plasma soluble LOX-1 levels. Exp Physiol, 2008; 93: 1085-1090

49) Serpente M, Fenoglio C, Villa C, Cortini F, Cantoni C, Ridolfi E, Clerici F, Marcone A, Benussi L, Ghidoni R, Martinelli BF, Gallone S, Cappa S, Binetti G, Franceschi M, Rainero I, Giordana MT, Mariani C, Bresolin N, Scarpini E, Galimberti D: Role of OLR1 and its regulating hsa-miR369-3p in Alzheimer's disease: genetics and expression analysis. J Alzheimers Dis, 2011; 26: 787-793

50) Tuten A, Aydemir B, Oncul M, Kiziler AR, Acikgoz AS, Korkmaz GG, Sozer V, Uzun H: The association of lectinlike oxidized LDL receptor 1 (LOX-1) K167N and 3'UTR188CT polymorphisms with maternal plasma soluble LOX-1 levels and preeclampsia risk in Turkish population. Arch Gynecol Obstet, 2015; 291: 563-571 